\title{
10 health stories that mattered this week: May 8-15
}

- Dr. David Sackett, founding chair of The Cochrane Collaboration and a medical pioneer, passed away at the age of 80. Sackett was noted for his contributions in three areas: research methods, evaluation of medical interventions, and educating clinicians to use best evidence. He published 10 books and 300 papers, including 48 in CMAJ.

- The world's first medical cannabis registry was launched by the McGill University Health Centre and the Canadian Consortium for the Investigation of Cannabinoids in Quebec. Clinical data will be collected from users of medical marijuana to help physicians and researchers better understand the safety and efficacy of using cannabis in medicine.

- Labels on nosodes should state that these homeopathic products have not been proven to prevent infection and children should receive all routine vaccinations even if they take nosodes, according to a position statement from the Canadian Paediatric Society. The society also recommends that Health Canada launch an education campaign to promote vaccination and provide the public with the best evidence of the benefits of vaccines and the risks of vaccine avoidance.

- Youth drinking is on the rise in Canada, with $67 \%$ of 15 -year-olds report- ing alcohol use in 2010, compared to $43 \%$ in 2002, reports the Organisation for Economic Co-operation and Development (OECD). In 2012, average consumption of alcohol in Canada was 8.2 litres among those aged 15 and older - below the OECD average of 9.1 litres - and the heaviest-drinking $20 \%$ of the population consumed $70 \%$ of all alcohol.

- The federal government's prohibition on using foreign-aid money to provide abortions in low-income countries would be overturned if the NDP were elected, stated party leader Thomas Mulcair. The party would also increase funding for women's organizations to support family planning, and reproductive and sexual health.

- Ontario has pledged $\$ 750$ million over three years to improve access to home care and provide more support for family caregivers. The money will fund an additional 80000 hours of nursing care, enhance support for personal support workers and provide greater choice for palliative and end-of-life care.

- Opioid addiction and overdose deaths are a growing public health concern in Alberta, but the government has been slow to recognize the problem, according to the College of Physicians and Surgeons of Alberta.
The powerful opioid fentanyl contributed to 120 deaths in the province last year and 50 deaths in the first two months of 2015.

- Provinces such as Nova Scotia are moving forward with regulations for e-cigarettes instead of waiting for guidance from Health Canada. Nova Scotia will become the first province to regulate the products on May 31, and British Columbia, Ontario and Quebec are all considering legislation on e-cigarette regulation.

- Dr. John O'Conner, the physician who went public with claims of high rates of rare cancers in Fort Chipewyan, which is near the Alberta oil sands, was dismissed by the health board of the remote community. He had provided health services to Fort Chipewyan for more than 15 years, but some members of the community were unhappy that he rarely visited in person and provided care remotely from Fort McMurray.

- A Canadian woman gave birth to a girl over the Pacific Ocean on an Air Canada plane flying from Calgary to Japan, with the assistance of physicians who were passengers on the flight. The new mother said she didn't know she was pregnant. Roger Collier, CMAJ

CMAJ 2015. DOI:10.1503/cmaj.109-5070 